\title{
Correlation between controlled lung collapse and early lung injury in dogs
}

\author{
GAOWANG LIU ${ }^{1 *}$, HONGYAN WANG $^{2}$, XIN LU $^{1}$, XIANFENG MA ${ }^{3}$, MING XIAO $^{4}$, \\ PAN XIAO $^{1}$, YAN WEI $^{1}$, MIAO YANG ${ }^{1}$, XUEYING YANG $^{5}$, XIAO YAN $^{1}$, AIXING ZHANG $^{1}$, \\ RUI LI ${ }^{1}$, JIANJUN TANG ${ }^{1}$, XIAOJUN LIU ${ }^{1}$, YATING ZHANG ${ }^{1}$ and JINFANG XIAO ${ }^{*}$ \\ ${ }^{1}$ Department of Anesthesiology, Nanfang Hospital, Southern Medical University, Guangzhou, Guangdong 510515; \\ ${ }^{2}$ Department of Cardiovascular Medicine, Xian Tao Hospital of Yangtze University, Wuhan, Hubei 433013; \\ ${ }^{3}$ Sino-French Institute of Nuclear Engineering and Technology, Sun Yat-Sen University, Zhuhai, Guangdong 519082; \\ ${ }^{4}$ Department of ENT, Zhongshan Hospital of Fudan University, Shanghai 200032; ${ }^{5}$ Department of Anesthesiology, \\ Sun Yat-sen Memorial Hospital, Sun Yat-sen University, Guangzhou, Guangdong 510515, P.R. China
}

Received September 29, 2017; Accepted June 27, 2018

DOI: 10.3892/etm.2018.6531

\begin{abstract}
A new type of pulmonary sequestration ventilator was used to compare the relationship between controlled lung collapse and early lung injury in thoracic surgery for dogs. Eighteen experimental dogs were randomly divided into three groups (G1-G3 groups). After general anesthesia, the shunt balance in lung was controlled and the pulmonary sequestration tube was placed in the femoral artery and vein, and the Swan-Ganz tube was placed into the right internal jugular vein as well. Two-lung ventilation (TLV) was first performed for $20 \mathrm{~min}$, followed by one-lung ventilation (OLV). The degree of collapse was $100 \%(\mathrm{G} 1), 90 \%(\mathrm{G} 2)$, and $50 \%$ (G3). Blood samples were extracted from femoral artery and jugular vein prior to collapse (T0), and at 30 (T1), 60 (T2), and 120 (T3) min after collapse for blood gas analysis to determine the shunt ratio (Qs/Qt). Blood samples were also subjected to enzyme linked immunosorbent assay (ELISA) to determine serum tumor necrosis factor- $\alpha$ (TNF- $\alpha$ ), intercellular immune adhesion molecule-1 (ICAM-1) and interleukin-6 (IL-6) levels. Arterial blood pressure, heart rate, pulmonary artery pressure and other physiological indicators were monitored during the experiment. Lung tissues were collected at T3 to calculate the wet/dry weight ratio (W/D). Histopathological changes were observed and compared by microscopic observation and blind scoring of pathological section after hematoxylin and
\end{abstract}

Correspondence to: Dr Jinfang Xiao, Department of Anesthesiology, Nanfang Hospital, Southern Medical University, 1838 Guangzhou North Avenue, Guangzhou, Guangdong 510515, P.R. China

E-mail: x7m3n8@163.com

${ }^{*}$ Contributed equally

Key words: one lung ventilation, lung collapse degree, lung injury eosin (H\&E) staining. There were no significant differences in the physiological indexes between the two groups during TLV $(\mathrm{P}>0.05)$. Mean pulmonary arterial pressure (MPAP) in G2 and G3 groups was significantly more stable than that in G1 group after OLV $(\mathrm{P}<0.05)$; shunt ratio $\mathrm{Qs} / \mathrm{Qt}, \mathrm{W} / \mathrm{D}$, and serum TNF- $\alpha$, ICAM-1 and IL-6 levels in the lung were decreased; and the degrees of pulmonary edema, hemorrhage, inflammatory cell infiltration and lung injury were also decreased. There was no statistically significant difference in each index at each time-point between G2 and G3 groups $(\mathrm{P}>0.05)$. Compared with complete lung collapse (collapse degree: $100 \%$ ), controlled lung collapse (collapse degree: $90 \%$ and $50 \%$ ) can better reduce the intraoperative lung injury, but there was no significant difference between the collapse degrees of 90 and $50 \%$.

\section{Introduction}

One-lung ventilation (OLV) is a common ventilation method used in thoracic surgery (1). A traditional double-lumen endotracheal tube is widely used in thoracic surgery. In order to provide enough space for surgical operation, the application of complete lung collapse is recommended. This traditional ventilation method can cause an imbalance in ventilation flow, thereby increasing the amount of lung shunting and leading to hypoxemia (incidence rate of 9-27\%) (2); and the secondary lung injury can occur. There are many studies on OLV, which are mostly limited by reducing lung injury via changing ventilation strategy or comparing the differences in lung injury caused by different lung isolation tools (3-5), but there is no study on the correlation between retaining the lung ventilation on operated side and lung injury. With the development of visual minimally-invasive technique of thoracic surgery, the prognosis of patients has attracted increased attention under the condition of completing the precision surgery $(6,7)$. At the same time, the prognosis of patients has been paid more attention $(8,9)$. In this study, a pulmonary sequestration tube device used to control the shunt in lung was developed (China 
patent: CN205073462 U) (10). which can control the degree of lung collapse during surgery while ensuing the surgical field; and the partial lung ventilation can be retained, so as to improve the prognosis of patients. From September 2015 to November 2016, the effects of complete lung collapse and controlled lung collapse on the pathology and physiology of lung were studied using the ventilator.

\section{Materials and methods}

Animals and materials. Eighteen experimental dogs of either gender were obtained from the Experimental Animal Center of Southern Medical University (Guangzhou, China). The mean animal weight was 9.5-15.5 kg. Before experimentation, the dogs were fasted for $12 \mathrm{~h}$ without water.

This study was approved by the Ethics Committee of Southern Medical University (Guangzhou, China).

Animal model preparation and grouping. After the peripheral veins were opened, $3 \%$ pentobarbital sodium $(30 \mathrm{mg} / \mathrm{kg}$, Sigma-Aldrich; Merck KGaA, Darmstadt, Germany), fentanyl ( $2 \mu \mathrm{g} / \mathrm{kg}$, Yichang Renfu Pharmaceutical Co., Ltd.; Jiangxi, China) and cis-carbene sulfonate $(0.1 \mathrm{mg} / \mathrm{kg})$ (Jiangsu Sinobiopharma Co.,Ltd., Jiangsu, China) were injected and the new single-lumen pulmonary sequestration tube was inserted. An anesthesia machine (Datex-Ohmeda, Inc., Madison, WI, USA) was used to control breathing. Sevoflurane was used to maintain anesthesia. The oxygen concentration $\left(\mathrm{FiO}_{2}\right)$ in the inhalation gas was $100 \%$, tidal volume was $10-15 \mathrm{ml} / \mathrm{kg}$, and respiratory rate was $12-16$ times/min. A monitor (mindary BeneView T8 China) was used to monitor and maintain $\mathrm{PEtCO}_{2}$ at $35-45 \mathrm{mmHg}(1 \mathrm{kPa}=7.5 \mathrm{mmHg})$. During the experiment, the muscle relaxation was maintained via intravenous injection of cis-triptolulfonate. Limb electrocardiogram was monitored and a temperature probe was inserted at $5 \mathrm{~cm}$ into the anus to monitor rectal temperature. A blood oxygen saturation detection probe was placed on the tongue to monitor oxygen saturation. During the experiment, the rectal temperature was maintained at $37.5-38.5^{\circ} \mathrm{C}$ at room temperature of $24-26^{\circ} \mathrm{C}$ and humidity of $67-73 \%$.

The femoral tube was dislocated to monitor the mean arterial pressure (MAP) and collect arterial blood. Femoral vein cannulation was performed to inject lactic acid Ringer's solution $\left(8 \mathrm{ml} \cdot \mathrm{kg}^{-1} \cdot \mathrm{h}^{-1}\right)$ using an infusion pump (Berenger, Berlin, Germany). A Swan-Ganz floating tube (Edwards Lifesciences, Irvine, CA, USA) was placed through right internal jugular vein. The tube was embedded in the pulmonary artery to monitor mean pulmonary arterial pressure (MPAP) and to collect mixed venous blood.

After the preparation of animal model, TLV was performed for $20 \mathrm{~min}$ and the dogs were randomly divided into 3 groups. The chest was opened between the fourth and fifth rib on the right side, and right lung collapse was induced. Left lung OLV was performed later. They were randomly divided into three groups according to the degree of right lung collapse with 6 dogs in each group: G1 group (100\% collapse, complete right lung collapse), G2 group (90\% collapse with 10\% ventilation) and G3 group (50\% collapse with 50\% ventilation). The catheter used in each group was tested by aerodynamics at the factory, and the correspondence between the lumen throughput
Table I. Correspondence between lumen throughput of intrapulmonary shunting balance tube and intracapsular pressure in tube wall (mean $\pm \mathrm{SD}$ ) $\mathrm{cmH}_{2} \mathrm{O}$.

\begin{tabular}{cccc}
\hline $\begin{array}{l}\text { Tube } \\
\text { no. }\end{array}$ & $\begin{array}{c}\text { 0\% ventilation } \\
(\mathrm{G} 1)\end{array}$ & $\begin{array}{c}10 \% \text { ventilation } \\
(\mathrm{G} 2)\end{array}$ & $\begin{array}{c}50 \% \text { ventilation } \\
(\mathrm{G} 3)\end{array}$ \\
\hline 1 & $30.4 \pm 1.1$ & $24.8 \pm 2.1$ & $18.8 \pm 3.0$ \\
2 & $28.7 \pm 0.8$ & $23.1 \pm 3.1$ & $18.0 \pm 2.5$ \\
3 & $29.4 \pm 1.2$ & $22.6 \pm 1.0$ & $17.5 \pm 1.7$ \\
4 & $24.1 \pm 0.3$ & $19.5 \pm 2.4$ & $15.6 \pm 1.8$ \\
5 & $25.7 \pm 0.9$ & $20.1 \pm 1.7$ & $17.8 \pm 1.7$ \\
6 & $27.4 \pm 0.4$ & $22.8 \pm 0.6$ & $16.2 \pm 1.4$ \\
7 & $29.5 \pm 1.3$ & $22.2 \pm 1.5$ & $17.8 \pm 1.5$ \\
8 & $31.4 \pm 0.4$ & $25.7 \pm 1.9$ & $19.4 \pm 2.4$ \\
9 & $28.7 \pm 1.0$ & $23.4 \pm 1.6$ & $17.7 \pm 2.9$ \\
10 & $35.1 \pm 1.3$ & $27.4 \pm 0.8$ & $21.8 \pm 1.5$ \\
11 & $30.5 \pm 2.1$ & $24.1 \pm 0.9$ & $19.8 \pm 2.2$ \\
12 & $33.0 \pm 2.2$ & $26.0 \pm 3.9$ & $22.3 \pm 2.2$ \\
13 & $27.8 \pm 1.9$ & $21.8 \pm 2.0$ & $19.7 \pm 1.9$ \\
14 & $32.3 \pm 1.1$ & $27.6 \pm 1.5$ & $23.2 \pm 2.1$ \\
15 & $30.0 \pm 0.9$ & $24.8 \pm 2.7$ & $18.8 \pm 2.6$ \\
16 & $26.3 \pm 1.5$ & $22.4 \pm 3.4$ & $17.0 \pm 3.4$ \\
17 & $28.1 \pm 1.9$ & $21.6 \pm 2.4$ & $18.1 \pm 1.7$ \\
18 & $26.9 \pm 0.6$ & $20.4 \pm 1.1$ & $17.4 \pm 1.2$ \\
\hline
\end{tabular}

Table II. Comparison of hemodynamic parameters among three groups of experimental dogs during OLV (mean $\pm \mathrm{SD}$ ).

\begin{tabular}{lclll}
\hline Group & T0 & \multicolumn{1}{c}{ T1 } & T2 & T3 \\
\hline MAP (mmHg) & & & & \\
G1 & $129 \pm 10$ & $113 \pm 14$ & $118 \pm 5$ & $115 \pm 3$ \\
G2 & $128 \pm 11$ & $120 \pm 7$ & $126 \pm 17$ & $118 \pm 9$ \\
G3 & $131 \pm 10$ & $125 \pm 7$ & $123 \pm 8$ & $120 \pm 6$ \\
HR (time/min) & & & & \\
G1 & $195 \pm 13$ & $182 \pm 15$ & $178 \pm 5$ & $185 \pm 9$ \\
G2 & $203 \pm 10$ & $185 \pm 16$ & $177 \pm 9$ & $171 \pm 8$ \\
G3 & $199 \pm 13$ & $179 \pm 8$ & $171 \pm 5$ & $177 \pm 6$ \\
MPAP (mmHg) & & & & \\
G1 & $13.0 \pm 2.2$ & $20.0 \pm 3.9^{\mathrm{a}}$ & $22.3 \pm 2.2^{\mathrm{a}}$ & $21.4 \pm 2.5^{\mathrm{a}}$ \\
G2 & $13.8 \pm 1.9$ & $17.8 \pm 2.0^{\mathrm{a}, \mathrm{b}}$ & $19.7 \pm 1.9^{\mathrm{a}, \mathrm{b}}$ & $20.5 \pm 2.2^{\mathrm{a}, \mathrm{b}}$ \\
G3 & $12.3 \pm 1.1$ & $16.0 \pm 1.5^{\mathrm{a}, \mathrm{b}}$ & $20.2 \pm 2.1^{\mathrm{a}, \mathrm{b}}$ & $21.5 \pm 1.8^{\mathrm{a}, \mathrm{b}}$ \\
\hline
\end{tabular}

a $\mathrm{P}<0.05$ compared with $\mathrm{T} 0$; ${ }^{\mathrm{b} P}<0.05$ compared with $\mathrm{G} 1$ group.

and the minimum cuff pressure in the tube wall was measured (Table I). After OLV for $20 \mathrm{~min}$, mixed venous blood and arterial blood were extracted from the femoral artery and jugular vein prior to TLV (T0), and at 30 (T1), 60 (T2), and $120 \mathrm{~min}$ (T3) after TLV for blood gas analysis (11-14). The remaining venous blood and arterial blood mixture was centrifuged $\left(4^{\circ} \mathrm{C}\right.$, $2080 \mathrm{x} \mathrm{g}$ ) for $12 \mathrm{~min}$ to collect the supernatant to quantify inflammatory factors. The supernatant was kept at $-80^{\circ} \mathrm{C}$ 


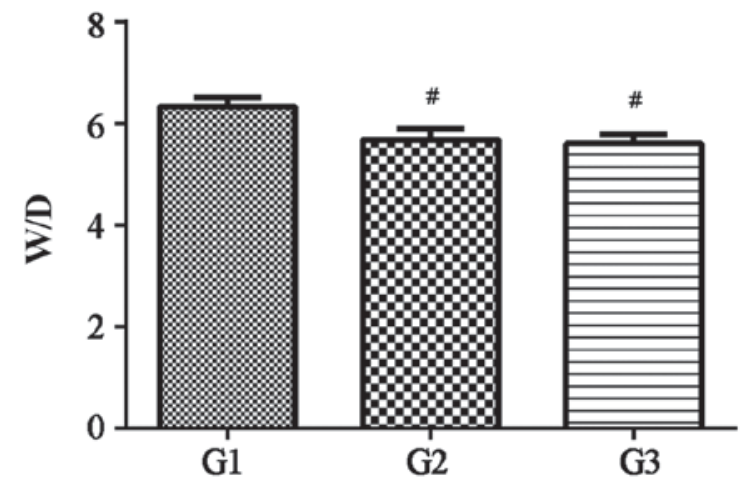

Figure 1. Effect of lung collapse degree on wet/dry ratio of lung (W/D). ${ }^{\#} \mathrm{P}<0.05$ compared with $\mathrm{G} 1$ group.

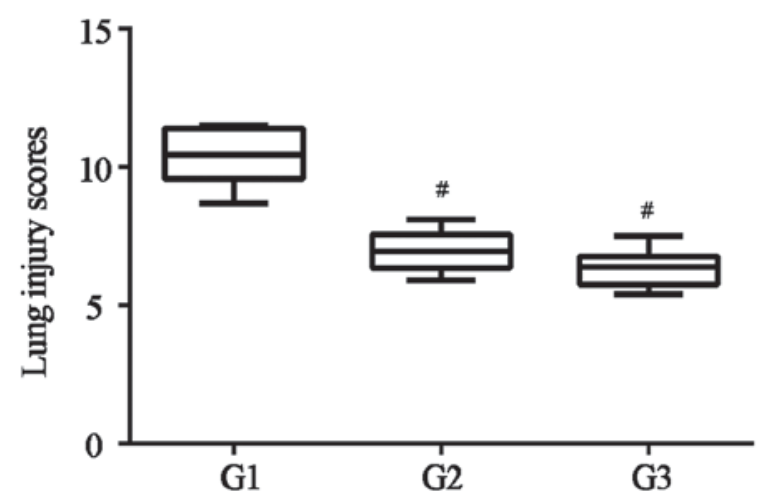

Figure 2. Effect of lung collapse degree on pathological score of lung tissues. ${ }^{\text {}} \mathrm{P}<0.05$ compared with G1 group.

before use. After OLV for 120 min, two small lung tissue pieces were collected from the ventilated side and the collapsed side, respectively. One lung tissue piece was used to determine W/D and the other piece was fixed in $10 \%$ formaldehyde solution for pathological examination.

Hemodynamic indicators. MAP, heart rate (HR) and MPAP were measured before blood sample collection for the comparison of hemodynamic stability.

Oxygenation indicators. Arterial blood was taken from the femoral artery at $20 \mathrm{~min}$ after TLV and at 30,60 and 120 min after OLV. A Swan-Ganz tube was used to collect mixed venous blood. Blood gas analyzer (Nova Biomedical, Waltham, MA, USA) was used to measure the arterial partial pressure of oxygen $\left(\mathrm{PaO}_{2}\right)$, arterial partial pressure of carbon dioxide $\left(\mathrm{PaCO}_{2}\right)$, oxygen saturation of arterial blood $\left(\mathrm{SaO}_{2}\right)$, partial pressure of oxygen in mixed venous blood $\left(\mathrm{PvO}_{2}\right)$, and mixed venous oxygen saturation $\left(\mathrm{SvO}_{2}\right)$. The pulmonary shunt rate was calculated according to the formula of the twocompartment model of pulmonary blood flow distribution: $\mathrm{Q}_{\mathrm{s}} / \mathrm{Q}_{\mathrm{t}}=\left(\mathrm{Cc}^{\prime} \mathrm{O}_{2}-\mathrm{CaO}_{2}\right) /\left(\mathrm{Cc}^{\prime} \mathrm{O}_{2}-\mathrm{CvO}_{2}\right) \times 100 \%$, where $\mathrm{Cc}^{\prime} \mathrm{O}_{2}$ is the blood oxygen content of pulmonary capillary.

Lung wet/dry weight ratio (W/D). After OLV for $20 \mathrm{~min}$, the chest was opened and lung tissue was collected and washed with saline $\left(4^{\circ} \mathrm{C}\right)$. Connective tissue was removed and filter paper was used to remove water on the surface. The tissue was then placed in a clean and dry glass bottle, accurately weighed and baked in an oven at $75^{\circ} \mathrm{C}$ for $24 \mathrm{~h}$ to calculate the W/D and to assess the degree of lung tissue edema.

Detection of serum TNF- $\alpha$ and IL-6 levels via ELISA. Frozen serum was allowed to defrost completely. The TNF- $\alpha$, ICAM-1 and IL-6 levels in serum were measured using ELISA kits according to manufacturer instructions.

Pathological examination of lung tissue. The middle lobe of the right lung was fixed in $10 \%$ neutral formaldehyde for $24 \mathrm{~h}$, followed by dehydration and paraffin embedding. The tissue was cut into $4 \mu \mathrm{m}$-thick sections which were stained via hematoxylin and eosin (H\&E). The histopathological changes of lung tissues were observed under light microscope (Olympus, Tokyo, Japan) and scored according to four categories: i) alveolar hyperemia, ii) hemorrhaging, iii) alveolar or vascular wall neutrophil infiltration or aggregation, and iv) alveolar wall thickening and/or hyaline membrane formation. Scoring was performed on a $0-4$ point scale according to the lesion severity; 0 point: no lesions or very mild lesions; 1 point: mild lesions; 2 points: moderate lesions; 3 points: severe lesions; 4 points: very severe lesions. The sum of all scores was taken as the total score of acute lung injury (ALI) (15).

Statistical analysis. Statistical Product and Service Solutions (SPSS) 19.0 software (IBM Corp., Armonk, NY, USA) was used for analysis, and measurement data were expressed as mean $\pm \mathrm{SD}$; comparisons between groups were performed using ANOVA and the post hoc test was LSD test. $\mathrm{P}<0.05$ indicates that the difference was statistically significant.

\section{Results}

Comparison of hemodynamic indexes. There were no significant differences in MAP and HR between groups at each time-point $(\mathrm{P}>0.05)$. MPAP of the $\mathrm{G} 2$ and $\mathrm{G} 3$ groups at $\mathrm{T} 1$, T2 and T3 were significantly lower than those in G1 group $(\mathrm{P}<0.05)$. No significant difference was found between $\mathrm{G} 2$ and G3 groups ( $\mathrm{P}>0.05$, Table II).

Oxygenation. Compared with the baseline values at T0, $\mathrm{PaO}_{2}$ and $\mathrm{PvO}_{2}$ were significantly decreased at all subsequent time-points $(\mathrm{P}<0.05)$. Qs/Qt was significantly increased $(\mathrm{P}<0.05)$, and changes in $\mathrm{PaCO}_{2}$ levels were not significant $(\mathrm{P}>0.05)$. Compared with those in $\mathrm{G} 1$ group, the $\mathrm{PaO}_{2}$ of $\mathrm{G} 2$ and G3 groups was significantly increased at T1, T2 and T3, while the Qs/Qt ratio was significantly decreased $(\mathrm{P}<0.05)$. There were no significant differences in $\mathrm{PaCO}_{2}$ and $\mathrm{PvO}_{2}$ between G1 and G2 or G3 groups at any time points $(\mathrm{P}>0.05$, Table III).

Changes in serum TNF- $\alpha$, ICAM-1 and IL- 6 levels. Compared with the baseline values at T0, all three groups showed significantly increased TNF- $\alpha$ levels at $\mathrm{T} 1, \mathrm{~T} 2$ and $\mathrm{T} 3(\mathrm{P}<0.05)$. TNF- $\alpha$ levels in G2 and G3 groups were significantly lower at $\mathrm{T} 1$, T2 and T3 than those in G1 group $(\mathrm{P}<0.05)$ at the corresponding time-points. No significant difference in TNF- $\alpha$ level was found between G2 and G3 groups at any time-point (P>0.05). A similar pattern was observed regarding ICAM-1 
Table III. Comparison of oxygenation indexes among three groups of experimental dogs during OLV (mean \pm SD).

\begin{tabular}{|c|c|c|c|c|}
\hline Group & T0 & $\mathrm{T} 1$ & $\mathrm{~T} 2$ & T3 \\
\hline \multicolumn{5}{|c|}{$\mathrm{PaCO}_{2}(\mathrm{mmHg})$} \\
\hline $\mathrm{G} 1$ & $40.1 \pm 2.1$ & $41.3 \pm 1.2$ & $39.6 \pm 3.5$ & $37.1 \pm 2.3$ \\
\hline $\mathrm{G} 2$ & $38.3 \pm 3.4$ & $40.6 \pm 2.8$ & $42.3 \pm 2.0$ & $39.4 \pm 3.1$ \\
\hline G3 & $41.9 \pm 1.9$ & $42.9 \pm 3.2$ & $40.8 \pm 2.7$ & $39.7 \pm 2.2$ \\
\hline \multicolumn{5}{|c|}{$\mathrm{PaO}_{2}(\mathrm{mmHg})$} \\
\hline $\mathrm{G} 1$ & $419.1 \pm 9.7$ & $107.6 \pm 12.6^{\mathrm{a}}$ & $173.4 \pm 11.7^{\mathrm{a}}$ & $189.3 \pm 15.2^{\mathrm{a}}$ \\
\hline G2 & $426.2 \pm 17.2$ & $158.9 \pm 13.8^{a}$ & $237.0 \pm 18.3^{\mathrm{a}}$ & $258.6 \pm 20.2^{\mathrm{a}}$ \\
\hline G3 & $410.5 \pm 13.5$ & $162.3 \pm 19.9^{a}$ & $258.0 \pm 20.1^{\mathrm{a}}$ & $261.8 \pm 16.5^{\mathrm{a}}$ \\
\hline \multicolumn{5}{|c|}{$\mathrm{PvO}_{2}(\mathrm{mmHg})$} \\
\hline G1 & $60.1 \pm 2.5$ & $44.9 \pm 3.7^{\mathrm{a}}$ & $49.6 \pm 2.1^{\mathrm{a}}$ & $50.9 \pm 3.1^{\mathrm{a}}$ \\
\hline $\mathrm{G} 2$ & $64.8 \pm 1.8$ & $51.3 \pm 2.6^{\mathrm{a}}$ & $55.0 \pm 2.8^{\mathrm{a}}$ & $54.3 \pm 2.7^{\mathrm{a}}$ \\
\hline G3 & $62.2 \pm 2.1$ & $53.7 \pm 2.8^{\mathrm{a}}$ & $54.8 \pm 1.1^{\mathrm{a}}$ & $53.6 \pm 1.6^{\mathrm{a}}$ \\
\hline \multicolumn{5}{|c|}{ Qs/Qt (\%) } \\
\hline $\mathrm{G} 1$ & $19.2 \pm 2.2$ & $47.7 \pm 1.9^{\mathrm{a}}$ & $40.2 \pm 4.0^{\mathrm{a}}$ & $38.7 \pm 3.5^{\mathrm{a}}$ \\
\hline G2 & $20.3 \pm 3.1$ & $40.1 \pm 2.3^{\mathrm{a}, \mathrm{b}}$ & $35.1 \pm 3.1^{\mathrm{a}, \mathrm{b}}$ & $32.1 \pm 1.6^{\mathrm{a}, \mathrm{b}}$ \\
\hline G3 & $18.0 \pm 1.6$ & $39.2 \pm 1.5^{\mathrm{a}, \mathrm{b}}$ & $32.9 \pm 2.3^{\mathrm{a}, \mathrm{b}}$ & $30.4 \pm 2.8^{\mathrm{a}, \mathrm{b}}$ \\
\hline
\end{tabular}

${ }^{\mathrm{a}} \mathrm{P}<0.05$ compared with $\mathrm{T} 0 ;{ }^{\mathrm{b}} \mathrm{P}<0.05$ compared with $\mathrm{G} 1$ group.

Table IV. Comparison of the effect of lung collapse degree on inflammatory indexes in mixed arterial and venous blood (mean $\pm \mathrm{SD})$.

\begin{tabular}{|c|c|c|c|c|c|}
\hline Inflammatory index & Group & T0 & $\mathrm{T} 1$ & $\mathrm{~T} 2$ & $\mathrm{~T} 3$ \\
\hline \multirow[t]{3}{*}{$\mathrm{TNF}-\alpha(\mathrm{pg} / \mathrm{ml})$} & G1 & $0.32 \pm 0.10$ & $6.84 \pm 1.12^{\mathrm{a}}$ & $8.28 \pm 1.07^{\mathrm{a}}$ & $8.64 \pm 1.12^{\mathrm{a}}$ \\
\hline & $\mathrm{G} 2$ & $0.38 \pm 0.10$ & $5.07 \pm 1.21^{\mathrm{a}, \mathrm{b}}$ & $5.88 \pm 0.68^{\mathrm{a}, \mathrm{b}}$ & $5.13 \pm 0.63^{\mathrm{a}, \mathrm{b}}$ \\
\hline & G3 & $0.31 \pm 0.14$ & $3.18 \pm 1.00^{\mathrm{a}, \mathrm{b}}$ & $4.61 \pm 0.67^{\mathrm{a}, \mathrm{b}}$ & $4.56 \pm 1.35^{\mathrm{a}, \mathrm{b}}$ \\
\hline \multirow[t]{3}{*}{ ICAM-1 (ng/ml) } & G1 & $7.14 \pm 1.05$ & $20.45 \pm 0.96^{\mathrm{a}}$ & $30.81 \pm 1.04^{\mathrm{a}}$ & $36.33 \pm 0.60^{\mathrm{a}}$ \\
\hline & G2 & $7.21 \pm 1.24$ & $15.74 \pm 1.44^{\mathrm{a}, \mathrm{b}}$ & $18.57 \pm 0.46^{\mathrm{a}, \mathrm{b}}$ & $20.00 \pm 0.65^{\mathrm{a}, \mathrm{b}}$ \\
\hline & G3 & $7.51 \pm 1.20$ & $9.92 \pm 0.98^{\mathrm{a}, \mathrm{b}}$ & $13.45 \pm 0.53^{\mathrm{a}, \mathrm{b}}$ & $14.62 \pm 0.43^{\mathrm{a}, \mathrm{b}}$ \\
\hline \multirow[t]{3}{*}{ IL-6 (pg/ml) } & G1 & $4.62 \pm 1.59$ & $63.36 \pm 6.42^{\mathrm{a}}$ & $66.08 \pm 7.04^{\mathrm{a}}$ & $54.07 \pm 5.29^{\mathrm{a}}$ \\
\hline & $\mathrm{G} 2$ & $5.06 \pm 1.50$ & $20.39 \pm 5.04^{\mathrm{a}, \mathrm{b}}$ & $26.62 \pm 3.96^{\mathrm{a}, \mathrm{b}}$ & $22.49 \pm 4.45^{\mathrm{a}, \mathrm{b}}$ \\
\hline & G3 & $5.67 \pm 1.84$ & $19.71 \pm 3.98^{\mathrm{a}, \mathrm{b}}$ & $28.19 \pm 3.13^{\mathrm{a}, \mathrm{b}}$ & $20.29 \pm 3.75^{\mathrm{a}, \mathrm{b}}$ \\
\hline
\end{tabular}

${ }^{\mathrm{a}} \mathrm{P}<0.05$ compared with $\mathrm{T} 0 ;{ }^{\mathrm{b}} \mathrm{P}<0.05$ compared with $\mathrm{G} 1$ group.

and IL-6 levels. Compared with the baseline values at T0, ICAM-1 and IL-6 levels were significantly increased at T1, T2 and T3 $(\mathrm{P}<0.05)$. ICAM-1 and IL-6 levels in G2 and G3 groups were significantly lower at T1, T2 and T3 than those in G1 group $(\mathrm{P}<0.05)$ at the corresponding time points. No significant differences in ICAM-1 and IL-6 levels were found between G2 and $\mathrm{G} 3$ groups at any time point $(\mathrm{P}>0.05$, Table IV).

Lung $W / D$. W/D of lung in each group was as follows: G1 group: $6.33 \pm 0.55$; G2 group: $5.69 \pm 0.67$; G3 group: $5.61 \pm 0.56$. W/D was significantly decreased in G2 and G3 groups compared with that in G1 group $(\mathrm{P}<0.05)$. No significant difference was found in W/D between $\mathrm{G} 2$ group and $\mathrm{G} 3$ group (P>0.05, Fig. 1).
Histopathological examination of lung tissues. The pathological examination of the collapsed side (right lung) was as follows: The G1 group showed significant changes in alveolar wall edema, pulmonary interstitial thickening, vascular congestion, serious inflammatory cell infiltration and alveolar structure damage. The alveolar structures of G2 and G3 groups were better than that in G1 group; the pulmonary interstitial and alveolar cavity exudates and inflammatory cell infiltration were significantly reduced compared with those in G1 group (Figs. 2 and 3).

ALI score in each group: G1 group: $10.33 \pm 0.98$ points; G2 group: $6.99 \pm 0.73$ points; G3 group: $6.34 \pm 0.68$ points. Compared with that in G1 group, the ALI scores of G2 and $\mathrm{G} 3$ groups were significantly reduced $(\mathrm{P}<0.05)$. There was no 
$\mathbf{A}$

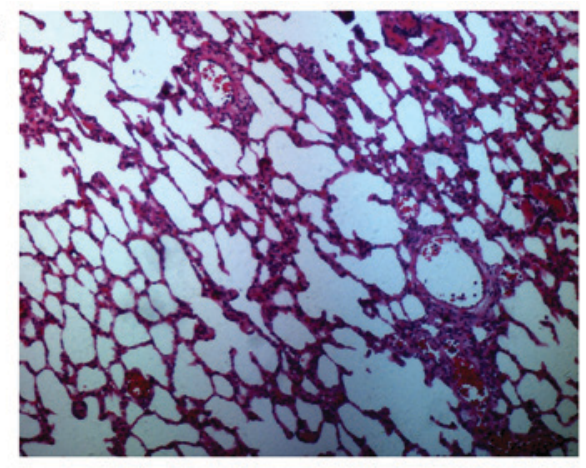

C

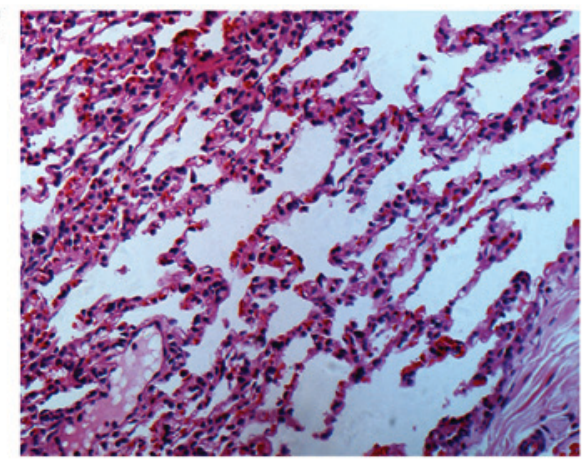

B

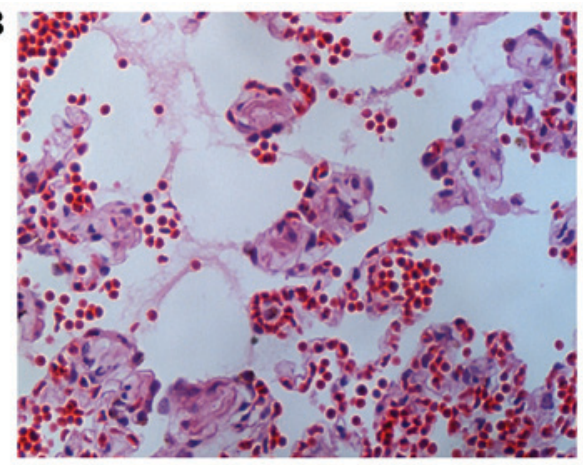

D

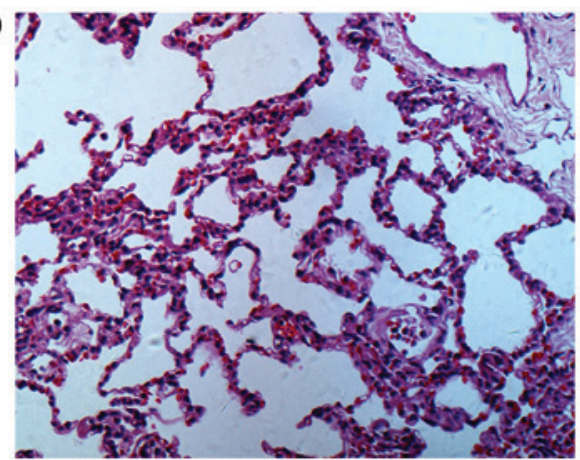

Figure 3. Effect of lung collapse degree on pathological changes of lung tissues (H\&E, x400 magnification). (A) G1 group; (B) G1 group; (C) G2 group; (D) G3 group.

significant difference in ALI score between G2 and G3 groups $(\mathrm{P}>0.05)$.

\section{Discussion}

OLV is a common ventilation method used in thoracic surgery. The lumen diameter of the traditional double-lumen tube is large and can cause damage to the glottis, throat edema and postoperative hoarseness. After intubation tube, the bronchofiberscope should be disconnected; otherwise, the displacement or dislocation may occur when the position is adjusted. During tube application, the lung is in a collapsed state. Although it is beneficial for surgical operation, OLV can cause lung collapse, which in turn leads to increased intrahepatic shunt, hypoxia and high airway pressure in the healthy lung, causing different degrees of lung injury later $(16,17)$. In this study, the controlled lung collapse based on the previous study on lung injury was proposed for the first time. The tube of controlling the shunt in the lung used in this study was characterized by thinner lumen, thus effectively reducing the airway damage. The size of sealing elements in the bronchial cavity can be controlled by controlling intake air volume combined with a pressure gauge to monitor internal pressure, which in turn controls the collapse degree on the surgical side of lung while ensuring the good surgical field. The ventilation on the surgical side of lung can improve the re-expansion pulmonary edema and secondary acute lung injury of patients during surgery, and improve oxygenation and hemodynamic status of patients. The lower end of tracheal catheter is porous and open, which needs no para-ventilation under general anesthesia. The intubation has a high success rate, no need for bronchofiberscope and large air flow, which can improve oxygenation and control the intraoperative ventilation of patients more precisely. It breaks through the traditional anesthesia method of complete lung collapse on the operated side, and reduce the damage of intubation tube to the bronchus. In particular, it can also improve the quality of oxygenation and prognosis of patients with chronic bronchitis and emphysema.

In this study, we found that $\mathrm{PaO}_{2}$ was significantly decreased while Qs/Qt was significantly increased (18) at 30 min during early-stage OLV due to no ventilation, the presence of blood flow in the collapsed lung and increased pulmonary shunting. $\mathrm{PaO}_{2}$ was gradually increased while $\mathrm{Qs} / \mathrm{Qt}$ was gradually decreased at $1 \mathrm{~h}$ after OLV, possibly due to the hypoxic pulmonary vasoconstriction (HPV) response that causes lateral pulmonary artery contraction on the collapsed side and increases the pulmonary vascular resistance. With these changes, the blood flow is transferred to the ventral side of lung, thereby improving the imbalanced ventilation/perfusion ratio, reducing pulmonary shunting, and maintaining normal $\mathrm{PaO}_{2}$ (19). In this study, the retention of partial alveolar ventilation in the experimental group significantly improved the shunt rate. At $1 \mathrm{~h}$ after OLV, the pulmonary shunting was significantly better than that in $\tau \eta \varepsilon$ complete collapse group, and the oxygenation condition was also significantly improved.

The overexpansion of alveoli during mechanical ventilation and the shear stress produced by repeated opening and closing, as well as local lung collapse can induce lung inflammatory responses and cause inflammation cascade initiation $(20,21)$. Pulmonary shunting, high airway pressure, lung ischemia-reperfusion injury and ventilation imbalance can damage alveolar capillary endothelium and stimulate alveolar macrophages to release a large number of proinflammatory mediators (22). Among the proinflammatory mediators, TNF- $\alpha$ has anti-infection and immune regulation 
functions, and it is one of the most important mediators of early state inflammation, as it can induce other inflammatory mediators and initiate inflammatory cascade reactions. ICAM-1 is an important immunoinflammatory molecule that mediates the adhesion reaction, which plays an important role in promoting the adhesion of inflammatory site, controlling tumor deterioration and metastasis and regulating the immune response. The expression of ICAM-1 is important to the degree of tissue injurv. IL-6 is the strongest inflammatory mediator of the proinflammatory cytokines, which is associated with the severity and duration of tissue damage and can reflect the severity of inflammatory responses due to surgical stress. In this study, controlled lung collapse and partial ventilation significantly improved lung injury degree during operation. TNF- $\alpha$, ICAM-1 and IL-6 levels were gradually increased over time in G1 group with complete lung collapse, indicating that OLV causes immune inflammatory response and lung injury. However, TTNF- $\alpha$, ICAM-1 and IL-6 levels in G2 and G3 groups were significantly lower than those in G1 group, suggesting that partial ventilation of the collapsed lung can reduce the severity of immune inflammatory reactions and protect lung tissue to a certain extent, improving prognosis and accelerating postoperative recovery.

Due to the imbalance of ventilation/perfusion ratio in OLV, hypoxemia is caused, triggering the production the release of a large number of inflammatory mediators, increasing the pulmonary capillary permeability (23) and increasing the lung water content on the collapsed side, ultimately leading to acute lung injury (ALI). The main pathological changes are extensive pulmonary inflammation, neutrophil aggregation, pulmonary interstitial edema, damaged pulmonary capillary endothelial cell, alveolar epithelial cell integrity, and penetration of protein-rich fluids into alveolar cavities. In this study, at $2 \mathrm{~h}$ after complete lung collapse, the dogs in G1 group showed significant hypoxemia, pulmonary edema and lipid peroxidation. Through pathological observation, alveolar wall edema, pulmonary interstitial thickening and serious inflammatory cell infiltration in alveolar cavities, and damaged alveolar structure were found. Our experiment successfully proved that the partial retention of collapsed lung ventilation can significantly improve oxygenation, reduce W/D of lung tissues and decrease plasma inflammatory factor levels without affecting the visual field. These results suggest that the controlled lung collapse can alleviate acute lung injury in experimental dogs to a certain extent.

In this study, the physiological indicators and inflammatory indicators in G2 and G3 groups were very similar, and there were usually no statistically significant differences in statistical analysis. The reasons may be that the current data measured are insufficient to produce the statistically significant differences due to the small sample size, so it is needed to further increase the sample size. In addition, there was partial alveolar ventilation in the two groups, but the maximum experimental time was set to only $2 \mathrm{~h}$, so there was no significant difference yet due to the short time. Therefore, the time and sample size should be increased for further study.

In this study, we confirmed that a new type of lung sequestration tube can control the degree of lung collapse during OLV in thoracotomy. The partial retention of collapsed lung ventilation can significantly improve the intraoperative oxygenation, thereby reducing lung injury caused by OLV during surgery without affecting the visual field. Further studies are still needed to explore whether this new type of tube can reduce the burden on other organs when used to protect the lung.

\section{Acknowledgements}

Not applicable.

\section{Funding}

This study was supported by Guangdong Province Science and Technology Planning projects: 00174990166341080, 2016B090918111, 701253476268, 2014A020212583 and Horizontal fund project (SZLB201218) (SZMR20120918) (JSLY20130118), China patent number ZL2015 2.0247672.2; ZL2017 30099023 7; ZL2017 3 0098968.7.

\section{Availability of data and materials}

The datasets used and/or analyzed during the current study are available from the corresponding author on reasonable request.

\section{Authors' contributions}

GL, HW and XLu analyzed and interpreted the patient data, and GL drafted the manuscript. XM, MX, PX, MY and XuY performed the experiment and participated in the design of the study. YW, XiY and AZ participated in the analysis and discussion of the data. RL and JT were responsible for the collection of the data and the follow-up management of the patients. XLi and $\mathrm{YZ}$ were responsible for the statistical analysis of the data. JX was devoted to designing the methods and revising the manuscript critically for important intellectual content. All authors read and approved the final manuscript.

\section{Ethics approval and consent to participate}

This study was approved by the Ethics Committee of Southern Medical University (Guangzhou, China).

\section{Patient consent for publication}

Not applicable.

\section{Competing interests}

Two authors of this study (JX and MX) are among the inventors of the patent CN205073462. According to Article 24 of the Intellectual Property Law of People's Republic of China and Article 60 of Chapter VII of the Patent Law of the People's Republic of China, the patent holders have permitted the authors to use the pulmonary sequestration tube device described in this patent, where the use is limited to projects for non-profit research.

\section{References}

1. Bernasconi F and Piccioni F: One-lung ventilation for thoracic surgery: Current perspectives. Tumori 103: 495-503, 2017. 
2. Seo JH, Cho CW, Hong DM, Jeon Y and Bahk JH: The effects of thermal softening of double-lumen endobronchial tubes on postoperative sore throat, hoarseness and vocal cord injuries: A prospective double-blind randomized trial. Br J Anaesth 116 282-288, 2016.

3. Lohser J and Slinger P: Lung injury after one-lung ventilation: a review of the pathophysiologic mechanisms affecting the ventilated and the collapsed lung. Anesth Analg 121: 302-318, 2015.

4. Falzon D, Alston RP, Coley E and Montgomery K: Lung isolation for thoracic surgery: From inception to evidence-based. J Cardiothorac Vasc Anesth 31: 678-693, 2017.

5. Clayton-Smith A, Bennett K, Alston RP, Adams G, Brown G, Hawthorne T, Hu M, Sinclair A and Tan J: A comparison of the efficacy and adverse effects of double-lumen endobronchial tubes and bronchial blockers in thoracic surgery: A systematic review and meta-analysis of randomized controlled trials. J Cardiothorac Vasc Anesth 29: 955-966, 2015.

6. Bendixen M, Jørgensen OD, Kronborg C, Andersen C and Licht PB: Postoperative pain and quality of life after lobectomy via video-assisted thoracoscopic surgery or anterolateral thoracotomy for early stage lung cancer: A randomised controlled trial. Lancet Oncol 17: 836-844, 2016.

7. Guerrero WG and González-Rivas D: Multiportal video-assisted thoracic surgery, uniportal video-assisted thoracic surgery and minimally invasive open chest surgery-selection criteria. J Vis Surg 3: 56, 2017.

8. Brat K, Tothova Z, Merta Z, Taskova A, Homolka P, Vasakova M Skrickova J, Sramek V, Olson LJ and Cundrle I Jr: Resting end-tidal carbon dioxide predicts respiratory complications in patients undergoing thoracic surgical procedures. Ann Thorac Surg 102: 1725-1730, 2016.

9. Magee MJ, Herbert MA, Tumey L and Prince SL: Establishing a dedicated general thoracic surgery subspecialty program improves lung cancer outcomes. Ann Thorac Surg 103: 1063-1069, 2017.

10. Xiao JF, Xiang B, Xiao M, Su L and Deng M: 10 years, controlled lungs balance air-separation pulmonary isolation catheter CN205073462 U, ZlL2015 $20247672.2,5050843$. The data filed: 22-04-2015. The data issued: 02-03-2018.

11. Ludwig C, Morand P, Schnell J and Stoelben E: Preserving middle lobe to improve lung function in non-small-cell lung cancer. Asian Cardiovasc Thorac Ann 17: 153-156, 2009.

12. Ichinose J, Kohno T and Fujimori S: Video-assisted thoracic surgery for metachronous lung cancer. Kyobu Geka 63: 969-972, 2010 (In Japanese).

13. Cai HB, Li YX and Li Z: Short term curative effect of video assisted thoracoscopic lobectomy for early-stage lung cancer. Indian J Cancer 51 (Suppl 2): e37-e41, 2015.
14. Xie D, Wang H, Fei K, Chen C, Zhao D, Zhou X, Xie B, Jiang L, Chen Q, Song N, et al: Single-port video-assisted thoracic surgery in 1063 cases: A single-institution experience. Eur J Cardiothorac Surg 49 (Suppl 1): i31-i36, 2016.

15. Sinclair SE, Kregenow DA, Lamm WJ, Starr IR, Chi EY and Hlastala MP: Hypercapnic acidosis is protective in an in vivo model of ventilator-induced lung injury. Am J Respir Crit Care Med 166: 403-408, 2002.

16. Potočnik I, Novak Janković V, Šostarič M, Jerin A, Štupnik T, Skitek M, Markovič-Božič J and Klokočovnik T: Antiinflammatory effect of sevoflurane in open lung surgery with one-lung ventilation. Croat Med J 55: 628-637, 2014.

17. Chai XQ, Ma J, Xie Y-H, Wang D and Chen KZ: Flurbiprofen axetil increases arterial oxygen partial pressure by decreasing intrapulmonary shunt in patients undergoing one-lung ventilation. J Anesth 29: 881-886, 2015.

18. Choi YS, Bae MK, Kim SH, Park JE, Kim SY and Oh YJ: Effects of alveolar recruitment and positive end-expiratory pressure on oxygenation during one-lung ventilation in the supine position. Yonsei Med J 56: 1421-1427, 2015.

19. Tojo K, Goto T and Kurahashi K: Protective effects of continuous positive airway pressure on a nonventilated lung during one-lung ventilation: A prospective laboratory study in rats. Eur J Anaesthesiol 33: 776-783, 2016.

20. Jin Y, Zhao X, Li H, Wang Z and Wang D: Effects of sevoflurane and propofol on the inflammatory response and pulmonary function of perioperative patients with one-lung ventilation. Exp Ther Med 6: 781-785, 2013.

21. García-de-la-Asunción J, García-del-Olmo E, Perez-Griera J, Martí F, Galan G, Morcillo A, Wins R, Guijarro R, Arnau A, Sarriá B, et al: Oxidative lung injury correlates with one-lung ventilation time during pulmonary lobectomy: A study of exhaled breath condensate and blood. Eur J Cardiothorac Surg 48: e37-e44, 2015.

22. Ding N, Wang F, Xiao H, Xu L and She S: Mechanical ventilation enhances HMGB1 expression in an LPS-induced lung injury model. PLoS One 8: e74633, 2013.

23. Helenius IT, Dada LA and Sznajder JI: Role of ubiquitination in Na,K-ATPase regulation during lung injury. Proc Am Thorac Soc 7: 65-70, 2010.

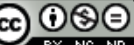

This work is licensed under a Creative Commons Attribution-NonCommercial-NoDerivatives 4.0 International (CC BY-NC-ND 4.0) License. 